\title{
On the Measurement of Perceived Consumer Risk
}

\author{
William J. Havlena \\ Graduate School of Management, Marketing Department, Rutgers University, \\ Newark, NJ 70102 \\ Wayne S. DeSarbo \\ School of Business Administration, Marketing and Statistics Departments, \\ University of Michigan, Ann Arbor, MI 48109-1234
}

\begin{abstract}
The role of perceived risk in consumer behavior has been studied extensively by academic researchers. This paper introduces a methodology for the measurement of the effects of product features, marketing mix components, and individual differences on perceived consumer risk based on theoretical foundations in the literature. A conjoint-type model based on paired comparison judgments is estimated to provide attribute weights. A modification of a stochastic multidimensional scaling-based vector model is then used to measure and summarize individual consumer differences with respect to the impact of brand attributes and marketing mix components on latent levels of perceived consumer risk. An illustration is provided using students' risk perceptions of sports cars.

Subject Areas: Consumer Behavior, Marketing Research, Multidimensional Scaling, and Statistical Methodology.
\end{abstract}

\section{INTRODUCTION}

The concept of perceived consumer risk has been a focus of attention in the marketing literature since Bauer [2] characterized consumer choice in terms of risk taking/reducing behavior. The concept is related to the fact that consumers are often uncertain about the outcome of a choice between brands in a particular product class and can become quite concerned about the consequences of a poor or wrong decision. Marketers spend billions of dollars annually seeking competitive advantage by attempting to reduce consumers' perceptions of risk associated with the purchase of their brand(s). Risks associated with the purchase of new products, for example, are often high because of the consumers' lack of information and prior experience. Risk for many types of packaged consumer goods is high because of a general concern for health and the threat of tampering. Products such as clothing, automobiles, and personal services often have high levels of social and/or psychological risk associated with them.

The goal of this research is the presentation of a methodology that will:

1. provide a multidimensional measurement scale of perceived consumer risk;

2. quantify the impact of brand features and marketing mix characteristics on levels of perceived consumer risk;

3. calculate the impact of individual differences on such perceptions of risk; and

4. allow for normative decision guidelines to the marketer on how to "optimally" manage/control perceived risk.

The next section presents a brief review of the research performed on perceived consumer risk, including a discussion of the limitations of the existing literature that are addressed in this paper. We then describe an illustrative experiment designed 
to collect data concerning perception of risk with respect to automobile purchases. A conjoint model and stochastic multidimensional scaling methodology are applied to these data to illustrate how perceived consumer risk can be operationalized. Finally, directions for future research, including a discussion of potential applications for measuring other latent constructs are presented.

\section{LITERATURE REVIEW}

Ross [22], Stem, Lamb, and MacLachlan [30], and Dowling [9] provided comprehensive reviews of the perceived risk literature related to consumer decision behavior. Past research in this area can be categorized into five major areas: (1) the nature of perceived consumer risk, (2) the relevant types of perceived consumer risk, (3) the relationship between perceived consumer risk and product class/features, (4) the effect of individual (demographic and psychological) differences on risk perception, and (5) the measurement of perceived consumer risk.

Past research in the area has identified two components of perceived consumer risk. Bauer stated that "consumer behavior involves risk in the sense that any action of a consumer will produce consequences which he cannot anticipate with anything approximating certainty, and some of which at least are likely to be unpleasant" [2, p. 390]. Subsequent research has tended to focus on these two aspects of risk: the consequences/importance of a loss and the likelihood of unfavorable outcomes [3] [4] [7] [19] [22]. These two components of risk, uncertainty and consequences, also have been found in research on perceived risk in nonmarketing contexts [25] [26] [27] [28]. In a consumer setting, Bettman [3] differentiated between two related risk constructs: inherent risk (which operates at the product category level) and handled risk (which involves the risk generated by a particular brand within the product class). Work in the area of perceived consumer risk also identified several categories of loss which impact overall perceived risk: performance, financial, safety, social, psychological, and time/opportunity [7] [12] [18] [21]. Jacoby and Kaplan [12] and Kaplan, Szybillo, and Jacoby [14] examined the relation of five categories of risk (performance, financial, safety, social, and psychological) to overall perceived consumer risk for twelve products and found significant differences across the product categories.

A number of studies have examined the relative riskiness of products drawn from different product classes [12] [14] [16] [29] [31]. A limited amount of published research has focused on risk within a given product class, generally in the context of brand choice [10] [19] [24]. However, none of these studies explicitly manipulated the level of perceived consumer risk or examined the relationship of brand risk to manipulable product differences.

\section{Limitations}

The studies discussed above generally examined perceived risk across a wide range of product categories or for a limited number of brands within a given category. The resulting measurements provide an ordering of categories or products concerning their risk potential. While this approach does provide some insight concerning consumers' perceptions of risk at a very general product class level, it does not yield any results which may be applied at the intra-category level of analysis. Also, these studies do not yield a metric measurement scale of risk nor 
do they relate risk directly to product and/or marketing mix characteristics. Clearly, additional research is needed in this area to formulate valid and reliable methods for assessing risk at intermediate and low levels of abstraction.

\section{PURPOSE}

This paper presents an operationalization of perceived risk in a managerial framework. The methodology employed in this study yields a metric measure of risk for alternative product designs and allows the researcher to measure the impact of specific product features or attributes on perceived consumer risk within one product category. The results of the analysis can be summarized in graphical form, which permits individual differences in risk perceptions to be clearly indicated. These results are obtained from paired comparisons measurements of the subjectspecific perceived risk of the alternative stimuli. Conjoint-type and multidimensional scaling models are used to derive the metric assessments of perceived consumer risk.

The research discussed here is limited to an examination of perceived consumer risk. The effect of such risk on utility, brand preference, or consumer decision making is not modelled. Although this study focuses on perceived risk and not on consumer choice, the measures could be used to incorporate perceived risk into a utility or choice model.

An illustration of this methodology using one product category, sports cars, is presented. The attributes were chosen to reflect the general types of risk identified in the studies cited earlier. Although the specific results are limited to the product category and the convenience sample employed in this application, the methodology can be applied to other products and services as well.

\section{ILLUSTRATION}

\section{Study Description}

Fifty upperclass undergraduate students enrolled in upper-level marketing courses volunteered to participate in a computer-administered data collection task dealing with automobile perceptions. The students were asked to make paired comparison judgments on 120 pairs of sports cars. The questionnaire elicited judgments about overall risk (i.e., Overall, which of the two sports cars is riskier to buy?), the six categories of perceived consumer risk, and overall preference. This measure of overall perceived consumer risk is consistent with earlier research in the area and allows subjects to consider both the likelihood and consequence aspects of risk [3]. This basic approach is similar to that used in conjoint analysis [23] [32].

The cars were profiled in a factorial main-effects design using thirteen attributes chosen on the basis of preliminary investigations with students. These thirteen attributes reflect the six categories of risk previously mentioned (performance, financial, safety, social, psychological, and opportunity/time loss) and incorporate variables related to risk reduction methods as recommended in the marketing literature [1] [20]. These design factors (labelled a through $\mathrm{m}$ ), their definitions, and levels appear in Table 1. The attribute levels were chosen after discussions with students and experts to provide meaningful differences between the alternatives 
Table 1: Design factors and levels.

\begin{tabular}{|c|c|c|c|c|}
\hline \multirow[b]{2}{*}{ Factor } & \multirow[b]{2}{*}{ Definition } & \multicolumn{2}{|c|}{ Levels } & \multirow{2}{*}{$\begin{array}{l}\text { Hypothesized } \\
\text { Effect on } \\
\text { Overall Risk } \\
\text { for Level } 2 \\
\end{array}$} \\
\hline & & 1 & 2 & \\
\hline a. Price & $\begin{array}{l}\text { The base sticker price of the } \\
\text { sports car }\end{array}$ & $\$ 20 \mathrm{~K}$ & $\$ 40 \mathrm{~K}$ & + \\
\hline b. Warranty & $\begin{array}{l}\text { The length of the warranty in } \\
\text { years/miles }\end{array}$ & $3 \mathrm{yr} / 30 \mathrm{~K}$ & $6 y r / 60 \mathrm{~K}$ & - \\
\hline $\begin{array}{l}\text { c. Country of } \\
\text { manufacture }\end{array}$ & $\begin{array}{l}\text { Whether the manufacturer was } \\
\text { located in Germany, Japan, } \\
\text { U.S.A., Korea, etc. }\end{array}$ & U.S.A. & Japan & - \\
\hline $\begin{array}{l}\text { d. Advertising } \\
\text { endorsement }\end{array}$ & $\begin{array}{l}\text { Whether a celebrity endorses } \\
\text { the sports car or it is endorsed } \\
\text { by Road \& Track magazine }\end{array}$ & Celebrity & Road \& Track & - \\
\hline $\begin{array}{l}\text { e. Safety test } \\
\text { results }\end{array}$ & $\begin{array}{l}\text { The analysis of the National } \\
\text { Highway Traffic Safety } \\
\text { Administration crash-test } \\
\text { injury data as published in } \\
\text { Consumer Reports }\end{array}$ & $\begin{array}{l}\text { Not } \\
\text { approved }\end{array}$ & Approved & - \\
\hline $\begin{array}{l}\text { f. Newness of } \\
\text { brand }\end{array}$ & $\begin{array}{l}\text { Whether the brand of sports } \\
\text { car, not the manufacturer, is } \\
\text { new for the model year or } \\
\text { whether the brand has been in } \\
\text { existence for at least one year }\end{array}$ & New & Existing & - \\
\hline $\begin{array}{l}\text { g. Manufacturer } \\
\text { reputation }\end{array}$ & $\begin{array}{l}\text { Whether the manufacturer is } \\
\text { best known for high } \\
\text { performance or for styling in } \\
\text { sports cars }\end{array}$ & Performance & Styling & $+1-\star$ \\
\hline $\begin{array}{l}\text { h. Repair } \\
\text { service }\end{array}$ & $\begin{array}{l}\text { The length of time required for } \\
\text { dealer service for most } \\
\text { common repairs \& maintenance }\end{array}$ & Same day & Next day & + \\
\hline $\begin{array}{l}\text { i. Loaner car } \\
\text { availability }\end{array}$ & $\begin{array}{l}\text { Whether or not the dealer } \\
\text { makes a loaner car available } \\
\text { for long term repairs }\end{array}$ & No & Yes & - \\
\hline $\begin{array}{l}\text { j. } \text { Miles } \\
\text { per gallon }\end{array}$ & $\begin{array}{l}\text { The average mileage rating } \\
\text { based on published test results }\end{array}$ & 20 & 40 & - \\
\hline $\begin{array}{l}\text { k. Special } \\
\text { financing }\end{array}$ & $\begin{array}{l}\text { Whether the dealer offers } \\
\text { reduced interest rates for } \\
\text { financing the purchase of a } \\
\text { sports car }\end{array}$ & None & $1.9 \%$ rate & - \\
\hline $\begin{array}{l}\text { 1. Braking } \\
\text { system }\end{array}$ & $\begin{array}{l}\text { Whether the sports car has } \\
\text { standard disk brakes or } \\
\text { computer-controlled anti-lock } \\
\text { brakes to prevent skidding }\end{array}$ & Standard & Anti-lock & - \\
\hline $\begin{array}{l}\text { m. Position in } \\
\text { product line }\end{array}$ & $\begin{array}{l}\text { Whether the sports car is the } \\
\text { standard model or the } \\
\text { luxury/top-of-the-line model }\end{array}$ & Slandard & Luxury & - \\
\hline
\end{tabular}

* A reputation based on styling is hypothesized to increase performance risk and decrease social/ psychological risk. The effect on overall perceived risk is uncertain. 
and were based on the range of actual levels available in the product class. The risk literature provides no theoretical guidance for the incorporation of interactions, while precedents exist for the use of main effects designs in the study of latent variables [6]. The order of the profiles, as well as the order of attributes within profiles, was randomized by computer for each subject to reduce order effects.

As a reward for successful completion of the computerized questionnaire, the students' names were entered into a lottery for a single cash prize of $\$ 100$. The instrument was pretested on a group of students in order to establish the relevance of the attributes, the credibility of the attribute levels, and the adequacy of the main effects design.

Given the complexity of the stimuli defined by the thirteen factors in Table 1, paired comparison judgments (rather than ratings) were collected in order to increase the reliability of the responses. Naturally, this increases the length of the task to some extent given the need to respond to 120 profile comparisons. However, we felt that despite the desirability of reducing the length of the task, it would be easier for the respondents to simply denote which one of two profiles involved more purchase risk than to evaluate each profile individually via rank orders or a numerical rating scale. This paired comparison format allows us the additional advantage of checking the consistency of responses in terms of the intransitivities of responses and circular triads. Kendall [15] provided a measure of consistency bounded between 0 (completely intransitive responses) and 1 (perfectly consistent responses). While there is some variance in the consistency of the subjects' responses, the mean coefficient of consistence was $.78(\sigma=.14)$, indicating reasonably consistent responses overall.

In addition, five different profiles were presented at the end of the paired comparison task to validate the conjoint task. The subjects were also asked to provide direct ratings of risk factors and their importance, to report previous experience with the product category (e.g., usage, ownership), and to answer a number of standard personality scales used in past research in the area of perceived risk (self-confidence, self-concept) [13] [17].

The average age of the respondents was 21.1 years and 44.7 percent were male. Of the respondents, 89.4 percent stated they presently drive an automobile and 76.6 percent claimed they own their own automobile; 48.9 percent stated that they either own or drive a sports car. Nearly one-third (31.9 percent) stated they alone were responsible for the purchase of their automobile. While 30 percent of the respondents claimed to have actual experience in buying a sports car, 63.8 percent of them indicated above average confidence in buying a sports car. Thus, the small illustrative sample contains a high proportion of automobile owners as well as present sports car drivers. This sample may be reflective of the large affluent and commuter-oriented student segment that typically attend the university.

Although data were collected for each of the six component types of risk, the analysis presented in this paper used only the overall measure of perceived consumer risk. The paired comparison judgments were analyzed using a modification of the PREFPAIRS procedure [5], which yields a set of attribute weights analogous to those produced in conjoint analysis. The analysis was performed at both the individual and the aggregate level. (Similar results were obtained with probit analyses performed on the paired comparisons data.) In addition, a probabilistic multidimensional scaling analysis [8] was performed on these paired comparisons data 
to yield a graphical representation of the relationship of product and marketing mix attributes to perceived risk. Vectors. in the perceptual space were used to represent the relative importance of the derived dimensions and significant features to overall risk at the individual level. The results of each analysis will be discussed individually.

\section{Hypotheses}

The hypothesized direction of the effect of each of the thirteen attributes is listed in Table 1. The hypotheses were based on findings reported by other researchers and on recommended risk reduction strategies found in the marketing literature [1]. Due to the increased financial risk produced by increased expenditures, we expect that the higher price level and decreased gas mileage should both result in higher overall risk. Similarly, longer warranty periods and the availability of special financing rates should reduce the risk. We hypothesize that foreign-made (and, in particular, Japanese) sports cars will be perceived to be more reliable and, hence, less risky than American cars. Expert endorsements have been suggested as a technique for risk reduction; we therefore hypothesize that an endorsement by Road \& Track should result in less risk than a celebrity endorsement. Safety test approval by Consumer Reports and special anti-lock braking systems are expected to reduce the level of safety risk, resulting in lower overall risk. A new brand is expected to have a higher level of uncertainty on several dimensions due to the consumer's lack of experience and information, producing lower overall risk for existing brands. The effect of manufacturer reputation (performance versus styling) is less obvious. A performance-based reputation should reduce performance risk and thus lead to lower overall risk. However, style-conscious consumers may perceive lower psychological and/or social risk for a sports car with a styling-based reputation. Therefore, it is hypothesized that the effect on overall risk will depend on the relative weight assigned to performance versus psychological/social risk. Due to the improved image of deluxe models, luxury models should be less risky than standard models. Due to the decreased risk of time loss, same day service and the availability of loaner cars should both decrease risk. Although the sign of the effect for twelve of the thirteen variables is hypothesized to be consistent across subjects, individual differences in risk perceptions will be reflected in differences in the relative weights of the variables (in the PREFPAIRS analysis) and vector orientations (in the multidimensional scaling analysis).

The thirteen attributes used in the conjoint design were selected to reflect the six types of risk identified in the existing literature. Thus, it is expected that up to six dimensions would appear in the multidimensional scaling analysis of the paired comparisons data.

\section{PREFPAIRS Analysis}

The aggregate PREFPAIRS analysis of the paired comparisons data yielded an $R^{2}$ of .923 , with eight of the thirteen variables significant at the .001 level. The signs of the coefficients are all in the hypothesized direction. The coefficients and standard errors appear in Table 2. (A probit analysis of the data yielded similar results.) Price has the strongest effect on overall perceived risk, with risk increasing as the price rises. Consumer Reports safety approval is next, having a risk-reducing effect. The existence of the brand in the previous year also has the effect of 
Table 2: PREFPAIRS results.

\begin{tabular}{lcc}
\hline Variable & Coefficient & Standard Error \\
\hline a. Price $=\$ 40 \mathrm{~K}$ & $.5083^{\mathrm{a}}$ & .0321 \\
b. Warranty = 6yr/60K & $-.1621^{\mathrm{a}}$ & .0231 \\
c. Country of manufacture = Japan & $-.1794^{\mathrm{a}}$ & .0191 \\
d. Advertising endorsement = Road \& Track & $-.0570^{\mathrm{b}}$ & .0202 \\
e. Safety test results = Approved & $-.3707^{\mathrm{a}}$ & .0194 \\
f. Newness of brand = Existing & $-.1931^{\mathrm{a}}$ & .0191 \\
g. Manufacturer reputation = Styling & $.0844^{\mathrm{a}}$ & .0191 \\
h. Repair service $=$ Next day & $.0456^{\mathrm{c}}$ & .0191 \\
i. Loaner car availability = Yes & -.0363 & .0191 \\
j. Miles per gallon $=40$ & $-.1319^{\mathrm{a}}$ & .0191 \\
k. Special financing $=1.9 \%$ rate & $-.0488^{\mathrm{c}}$ & .0191 \\
l. Braking system $=$ Anti-lock & $-.0906^{\mathrm{a}}$ & .0191 \\
m. Position in product line = Luxury & -.0350 & .0191 \\
\hline
\end{tabular}

${ }^{a}$ significant at $p<.001$

bsignificant at $p<.01$

significant at $p<.05$

Note: A positive coefficient indicates that the level of the attribute specified in the first column increases perceived risk relative to the alternative level listed in Table 1. A negative coefficient indicates that the listed level results in decreased perceived risk.

reducing risk. The other five variables that reached significance at the .001 level are (in decreasing order of impact): country of manufacture, warranty length, gas mileage, braking system, and styling/performance reputation. The last variable (styling/performance) had a positive impact, indicating that a reputation for styling tended to increase perceived risk, while a performance reputation decreased risk. The advertising endorsement source was significant at the .01 level, with an expert endorsement reducing risk relative to a celebrity endorsement. Speed of service and the availability of special financing were significant at the .05 level. Only the availability of loaner cars and the position of the car in the product line failed to reach significance at the .05 level. Thus, as in conjoint analysis [11], an aggregate optimal perceived risk profile incorporating the information contained in Table 2 could be devised. In addition, predictive indices of perceived consumer risk could be provided by simply substituting any desired profile and applying these estimated coefficients.

This PREFPAIRS analysis was also performed individually for each of the fifty students to investigate individual differences in their perceptions of overall perceived risk with respect to sports car purchases. (As noted earlier, probit analyses were also conducted with similar results for both aggregate and individual analyses.) Rather than present a complex table (a matrix of 50 subjects and 14 coefficients), we performed a multidimensional scaling analysis of these paired comparison judgments to visually portray the nature of such individual differences.

\section{MDS Analysis}

We modified the DeSarbo, Oliver, and DeSoete [8] stochastic multidimensional scaling (MDS) procedure designed for the analysis of paired comparison 
Table 3: Correlations between dimensions and design variables.

\begin{tabular}{lccc}
\hline & \multicolumn{3}{c}{ Dimension } \\
\cline { 2 - 4 } Variable & 1 & 2 & 3 \\
\hline a. Price $-\$ 40 \mathrm{~K}$ &. .872 & .150 & .398 \\
b. Warranty = 6yr/60K & -.270 & -.203 & -.053 \\
c. Country of manufacture = Japan & -.091 & -.150 & -.733 \\
d. Advertising endorsement = Road \& Track & -.073 & -.104 & -.073 \\
e. Safety test results = Approved & -.239 & -.897 & -.265 \\
f. Newness of brand = Existing & -.144 & -.230 & -.450 \\
g. Manufacturer reputation = Styling & .123 & .067 & .035 \\
h. Repair service - Next day & .031 & .092 & .041 \\
i. Loaner car availability = Yes & -.050 & -.011 & -.055 \\
j. Miles per gallon = 40 & -.187 & -.160 & -.074 \\
k. Special financing = 1.9\% rate & -.022 & -.029 & -.080 \\
1. Braking system = Anti-lock & -.141 & -.080 & -.059 \\
m. Position in product line = Luxury & -.040 & -.003 & -.046 \\
\hline
\end{tabular}

Note: Correlation values exceeding .40 in absolute value are underlined.

judgments. The methodology is particularly useful in our context given the paired comparisons data and the conjoint design matrix which can be used to reparameterize the hypothetical product locations. We performed the analysis in $T=1,2,3$, and 4 dimensions using the reparameterization option for the stimulus profiles. Based on goodness of fit $\left(R^{2}=.76\right)$ and minimum Akaike Information Criterion (AIC), we selected the $T=3$ dimensional solution as the most parsimonious. Table 3 presents the correlations of the three dimensions (profile coordinates) with the design matrix after a varimax rotation of the solution was performed. Correlation values exceeding .40 in absolute value are underlined in Table 3 . As shown, the first dimension clearly reflects price, the second dimension mainly reflects safety concerns, and the third dimension represents country of manufacture and newness (new versus existing) of the sports car brand. Recall, these design variables were also quite significant in the PREFPAIRS analysis presented in Table 2. As stated earlier, the four variables comprising the three dimensions reflect three types of risk: financial, safety, and performance.

Figure 1 presents the joint space plots for the first two dimensions. The fifty subjects are represented by vectors, and the profiles by uppercase letters. The table and figure illustrates how price, country of manufacture, safety, and newness of brand relate to the first two dimensions. Here, high price, no safety approval, USA origin, and new brand all increase perceived risk. The subject vector orientations point in the direction of higher risk. Note that profiles $M, O, A, K$, and $I$ are uniformly evaluated as having higher perceived risk.

A calculated measurement scale of perceived risk, $U_{i j}$, can be obtained for each subject and profile via the scalar products of profile coordinates from the MDS results onto the consumer vectors produced by the same analysis. In the current illustration, profiles $\mathrm{M}, \mathrm{O}, \mathrm{A}, \mathrm{K}$, and I have higher average risk scores. Thus, the methodology can provide a metric measurement of risk for any profile defined in terms of these design variables by consumer. Note that these latent risk 
Figure 1: Multidimensional scaling results (dimensions 1 and 2).

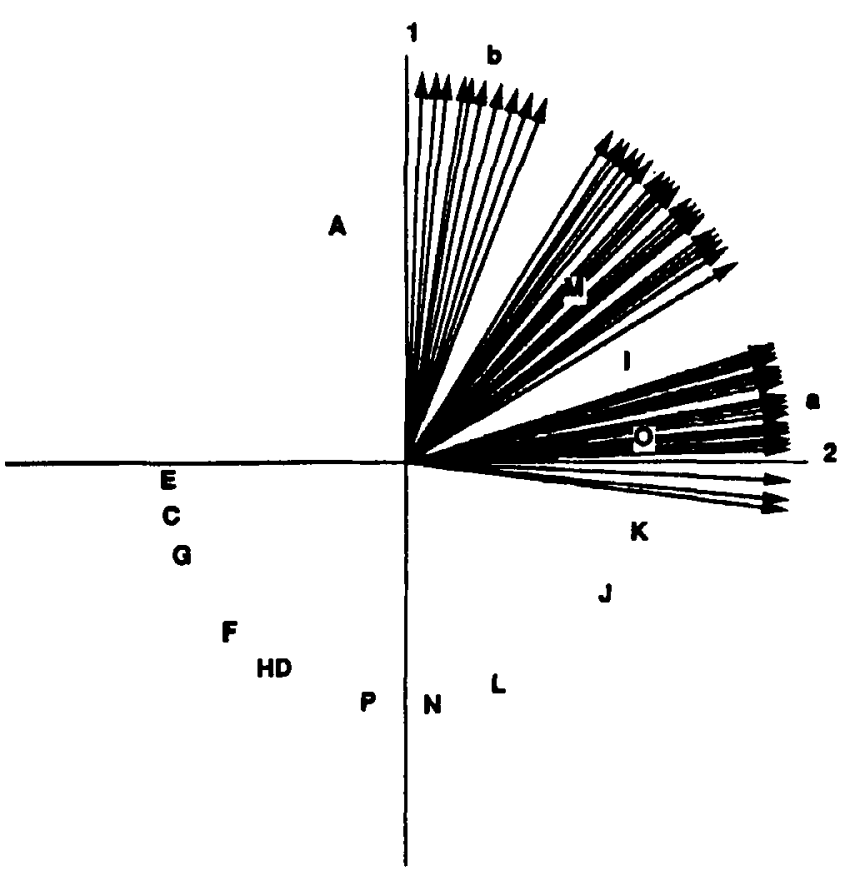

scores can also be calculated for any new profile(s) of sports cars in this illustration. One can easily convert a vector of brand attributes $\left(\mathbf{H}_{j l}\right)$ into a specific brand location in the $T$-dimensional derived joint space. With the estimated respondent vector orientations, a scalar product can be taken with this new brand(s) and each of these derived respondent vectors to produce a predicted perceived risk score. This procedure was performed with five holdout profiles for validation and is presented in the next section.

Finally, note the nature of the individual differences in Figure 1 as evidenced by the different vector directions for the 50 subjects. The majority of vectors can be reflected or rotated to lie in one quadrant of the two dimensional plot, indicating an interesting perspective on individual differences regarding the perception of risk. As hypothesized, the subjects appear to be fairly congruent concerning which end of each of the three dimensions indicates increased risk. However, there is substantial variation in how the subjects weight these dimensions in assessing overall risk. This can be seen by examining two individuals more closely. The vectors representing subjects $a$ and $b$ are labelled in the figure. The vector directions for subject a indicate that he/she places high weights on dimension 2 (i.e., safety concerns) with little or no weight on dimension 1 (i.e., price). The projections onto the vectors indicate that profiles $\mathrm{O}, \mathrm{I}$, and $\mathrm{K}$ are viewed as the most risky. On the other hand, subject $b$ 's perceptions of risk are primarily influenced by price. Safety concerns have almost no weight in this subject's perceived risk ratings. For this subject, profiles $\mathbf{M}$ and $\mathbf{A}$ have the highest perceived risk. 


\section{Validation}

As previously stated, the five profiles were included in the computerized questionnaire for validation purposes. After completing the paired comparisons task, each subject was asked to evaluate each of the five experimental profiles as to their overall level of perceived risk. The response scale was a 0 to 9 integer scale $(0=$ lowest perceived risk, $9=$ highest perceived risk). These responses were then correlated with the predicted values formed by (1) the group PREFPAIRS function and (2) each individual's PREFPAIRS function. The resulting correlations were .383 for the group function and .421 for the individual functions for the entire sample. The distribution of the individual validation correlations tends to be bimodal, with a large group of subjects whose responses validate quite well $(r \geq .7)$ and a large group of subjects whose responses do not $(r \leq .4)$. For this latter group, it may be that (1) the task was too burdensome and their interest waned, (2) the change in the response mode from the paired comparisons task was confusing, or (3) perhaps a main effects only function was inappropriate. Interestingly enough, the validation correlations produced with the use of the stochastic MDS model ( $r=.458$ for the entire sample) displayed a distribution similar to that obtained from the PREFPAIRS analysis.

\section{DISCUSSION}

The PREFPAIRS analysis and the multidimensional scaling together provide a metric operationalization of perceived consumer risk that (1) measures risk in a multidimensional framework, (2) relates perceived consumer risk to brand attributes, and (3) indicates the effect of individual differences on overall consumer risk perceptions. The PREFPAIRS analysis provides a clear assessment of the impact of product variables on risk, allowing the researcher to understand the effect of design and marketing strategies on the perceived risk profile of a product. The aggregate-level analysis presented in the paper provides a metric measure of perceived risk for each product profile across subjects. While such an analysis was also performed by subject, the resulting table of individual coefficients and significance levels is quite messy to display and difficult to summarize. The multidimensional scaling output provides a concise representation of the relationship of product variables to risk at the aggregate level and the relative importance of attributes at the individual (or market segment) level. The individual subject vectors provide a graphical depiction of each subject's sensitivity to the risk factors included in the study. Note, attribute vectors can also be imposed in such figures that indicate the relationship of each design attribute with each dimension as reflected in Table 3. Thus, a single map portrays both the impact of design features on perceived consumer risk and individual differences in the weights assigned to those features. Both methodologies can be utilized to produce individual level predictions of consumer risk for a given product profile. These risk measurements might then be incorporated into a model of product/brand preference or choice.

The results of the study clearly indicate the multidimensional nature of perceived consumer risk. The PREFPAIRS analysis revealed that eight of the thirteen product characteristics were significantly related to perceived risk. The four most significant variables (for both the PREFPAIRS and MDS analyses) appear to reflect three different types of risk (financial versus safety versus performance), lending 
support for earlier findings conceming the types of perceived consumer risk [7] [12] [18] [21]. The MDS analysis also indicates the presence of clear individual differences with regard to the relative impact of these product characteristics on overall perceived consumer risk.

\section{Limitations}

The results of the study clearly indicate the relationship of the thirteen design and marketing factors to perceived consumer risk. However, there are a few limitations which should be noted. The procedure requires a large number of comparison judgments. In the current illustration, eight paired comparison judgments were solicited for each of the 120 pairs of sports cars. The length of the task and number of comparisons may have had a negative effect on the subjects' carefulness in completing the instrument and may account for the mixed validation results we observed. These results may also be due to the presence of interactions between the product attributes, which were not measured. However, the number of attributes and levels required to adequately reflect the determinants of risk made a longer task prohibitive. In addition, although the student sample expressed a moderate amount of prior familiarity, interest, and experience in the product category, one obviously cannot generalize the results of this small illustration.

\section{Future Research}

This study provided an illustration of the measurement of the effect of product and marketing variables on overall perceived risk at the consumer level. Clearly, there is the need to perform such studies on random samples from real target markets. Future research will also extend the approach presented in this paper to consider the impact of the same variables on the individual component types of perceived consumer risk (performance, financial, safety, social, psychological, and opportunity/time loss) and the relationship of these component types to overall perceived risk and product preferences. Future studies should also measure the effect of individual differences at the consumer level on reactions to product attributes, with a view toward explaining individual preferences and perceived consumer risk in a manner that may prove useful managerially as a basis for segmentation. For example, the relationship of risk perceptions to categories of adopters (e.g., innovators, early adopters, and laggards) could be examined. Finally, other more efficient experimental designs for paired comparisons elicitation should be tested to reduce potential respondent fatigue. [Received: March 22, 1989. Accepted: June 28, 1990.]

\section{REFERENCES}

[1] Assael, H. Consumer behavior and marketing action (2nd ed.). Boston, MA: Kent Publishing Co., 1984.

[2] Bauer, R. A. Consumer behavior as risk taking. In R.S. Hancock (Ed.), Proceedings of the 43rd Conference of the American Marketing Association, Chicago, IL: American Marketing Association, 1960, 389-398.

[3] Bettman, J. R. Perceived risk and its components: A model and empirical test. Journal of Marketing Research, 1973, 10, 184-190.

[4] Bettman, J. R. Information integration in consumer risk perception: A comparison of two models of component conceptualization. Journal of Applied Psychology, 1975, 60(3), 381-385.

[5] BMDP manual, Los Angeles: BMDP Statistical Software, Inc., 1985. 
[6] Burke, R. R., DeSarbo, W. S., Oliver, R. L., \& Robertson, T. S. Deception by implication: An experimental investigation. Journal of Consumer Research, 1988, 14, 483-494.

[7] Cunningham, S. M. The major dimensions of perceived risk. In D.F. Cox (Ed.), Risk taking and information handling in consumer behavior. Boston, MA: Harvard University, 1967, 82-108.

[8] DeSarbo, W. S., Oliver, R. L., \& DeSoete, G. A probabilistic multidimensional scaling vector model. Applied Psychological Measurement, 1986, 10, 79-98.

[9] Dowling, G. R. Perceived risk: The concept and its measurement. Psychology and Marketing, 1986, 3, 193-210.

[10] Dunn, M. G., Murphy, P. E., \& Skelly, G. U. The influence of perceived risk on brand preferences for supermarket products. Journal of Retailing, 1986, 62(2), 204-216.

[11] Green, P. E., \& Rao, V. R. Conjoint measurement for quantifying judgmental data. Journal of Marketing Research, 1971, 8, 355-363.

[12] Jacoby, J., \& Kaplan, L. B. The components of perceived risk. In M. Venkatesan (Ed.), Proceedings of the 3rd Annual Conference of the Association for Consumer Research, Chicago, IL: Association for Consumer Research, 1972, 382-393.

[13] Janis, I. L., \& Field, P. B. Sex differences and personality factors related to persuasibility. In I.L. Janis, C.I. Hovland, P.B. Field, H. Linton, E. Graham, A.R. Cohen, D. Rife, R.P. Abelson, G.S. Lesser \& B.T. King (Eds.), Personality and persuasibility. New Haven, CT: Yale University Press, 1959, 55-68.

[14] Kaplan, L. B., Szybillo, G. J., \& Jacoby, J. Components of perceived risk in product purchase: A cross-validation. Journal of Applied Psychology, 1974, 59(3), 287-291.

[15] Kendall, M. G. Rank correlation methods (4th ed.). London: Griffin Press, 1970.

[16] Locander, W. B., \& Hermann, P. W. The effect of self-confidence and anxiety on information seeking in consumer risk reduction. Journal of Marketing Research, 1979, 16, 268-274.

[17] Malhotra, N. K. A scale to measure self-concepts, person concepts, and product concepts. Journal of Marketing Research, 1981, 18, 456-464.

[18] Perry, M., \& Hamm, B. C. Canonical analysis of relations between socioeconomic risk and personal influence in purchase decisions. Journal of Marketing Research, 1969, 6, 351-354.

[19] Peter, J. P., \& Ryan, M. J. An investigation of perceived risk at the brand level. Journal of Marketing Research, 1976, 13, 184-188.

[20] Robertson, T. S., Zielinski, J., \& Ward, S. Consumer behavior. Glenview, IL: Scott, Foresman, \& Co., 1984.

[21] Roselius, T. Consumer rankings of risk reduction methods. Journal of Marketing, 1971, 35, 56-61.

[22] Ross, I. Perceived risk and consumer behavior: A critical review. In M.J. Schlinger (Ed.), Advances in consumer research (Vol. 2). Urbana, IL: Association for Consumer Research, 1975, 1-19.

[23] Safizadeh, M. H. The internal validity of the trade-off method of conjoint analysis. Decision Sciences, 1989, 20, 451-461.

[24] Schiffman, L. G. Perceived risk in new product trial by elderly consumers. Journal of Marketing Research, 1972, 9, 106-108.

[25] Slovic, P. Perception of risk. Science, 1987, 236, 280-285.

[26] Slovic, P., Fischhoff, B., \& Lichtenstein, S. Rating the risks. Environment, 1979, 21, 14-20, 36-39.

[27] Slovic, P., Fischhoff, B., \& Lichtenstein, S. Facts and fears: Understanding perceived risk. In R. Schwing \& W.A. Albers, Jr. (Eds.), Societal risk assessment: How safe is safe enough? New York: Plenum, 1980.

[28] Slovic, P., Fischhoff, B., \& Lichtenstein, S. Characterizing perceived risk In R.W. Kates, C. Hohenemser, \& J.X. Kasperson (Eds.), Perilous progress: Managing the hazards of technology. Boulder, CO: Westview, 1985.

[29] Spence, H. E., Engel, J. F., \& Blackwell, R. D. Perceived risk in mail-order and retail store buying. Journal of Marketing Research, 1970, 7, 364-369.

[30] Stem, D. E., Jr., Lamb, C. W., Jr., \& MacLachlan, D. L. Perceived risk: A synthesis. European Journal of Marketing, 1977, 11(4), 312-319.

[31] Zikmund, W. G., \& Scott, J. E. A multivariate analysis of perceived risk, self-confidence and information sources. In S. Ward \& P. Wright (Eds.), Advances in consumer research (Vol. 1). Chicago, IL: Association for Consumer Research, 1973, 406-416.

[32] Zufryden, F. S. Using conjoint analysis to predict trial and repeat-purchase patterns of new frequently purchased products. Decision Sciences, 1988, 19, 55-71. 
William J. Havlena is Associate Professor of Marketing at the Graduate School of Management at Rutgers University in Newark, New Jessey. Dr. Havlena received a Ph.D. in marketing from Columbia University. His research interests lie in the study of consumer behavior, especially the role of emotions in various consumption situations. Dr. Havlena has published in the Journal of Consumer Research.

Wayne S. DeSarbo is the Sebastian S. Kresge Distinguished Professor of Marketing and Statistics at the Graduate School of Business of the University of Michigan. He received his B.S. degree in economics from the Wharton School of the University of Pennsylvania. He has M.A. degrees in sociology, administrative science/O.R., and marketing from Yale University and the University of Pennsylvania. Dr. DeSarbo obtained his Ph.D. in marketing and statistics from the University of Pennsylvania, and completed post doctorate work in operations research and econometrics there. He has published over $\mathbf{8 0}$ articles in such journals as the Journal of Marketing Research, Psychometrika, Journal of Consumer Research, Journal of Mathematical Psychology, Marketing Science, Journal of Classification, and others. His methodological interests lie in multidimensional scaling, classification, and multivariate statistics, especially as they pertain to substantive marketing problems in positioning, market structure, consumer choice, market segmentation, and competitive strategy. He is currently president of the Statistics in Marketing Section of the American Statistical Society. Dr. DeSarbo is a member of AMA, ORSA/TIMS, Psychometric Society, ASA, RSS, Classification Society, INSNA, IMS, Econometric Society, ACR, the Decision Sciences Institute, and APA. He serves on the review boards of Marketing Science, Journal of Consumer Research, Marketing Letters, Journal of Classifcation, and Journal of Marketing Research. 